\title{
NARRADORES DE JAVÉ: ARGUMENTOS PARA PENSAR A MODERNIDADE*
}

\author{
Cláudio Pellini Vargas, \\ da Universidade Federal de Juiz de Fora/MG \\ antonio Flavio Barbosa Moreira, \\ da Universidade Católica de Petrópolis/RJ
}

\begin{abstract}
Resumo: O presente trabalho visa discutir a crise da Modernidade, com base nas questões sugeridas pelo filme Narradores de Javé, dirigido por Eliane Caffé. Indagamos: que tipos de documentos registram as "verdades"? Quem pode dizer o que é ou não é a "verdade"? Qual é a diferença entre o que se diz ou o que se escreve? Existe significado fora do "método"? Sustentamos que a obra em pauta proporciona valiosas reflexões acerca do embate existente entre o pretenso cientificismo moderno e suas consequências "pós-modernas".
\end{abstract}

Palavras-chave: Modernidade. Pós-modernidade. Significado.

INTRODUÇÃO

Nenhum homem em sua sobriedade atinge o estado de inspiração...

(Platão)

A pluralidade de significados, característica dos períodos em que o debate de ideias é livre e intenso, leva-nos a uma situação de constantes questionamentos, seja na educação, na política, na religião, ou ainda na ciência. Entendemos que tal pluralidade tem sido retomada por recentes intelectuais, ${ }^{1}$ o que nos leva a afirmar que coexistimos em um período de dificuldades de escolhas. O fato parece intimidar parte da sociedade moderna,

\footnotetext{
* Artigo recebido em 10/1/2011 e aprovado em 20/6/2011.
} 
mas sugere novas formas de pensar o homem e suas relações com as diversas áreas do conhecimento.

"A crise [...] é o estado normal da sociedade humana" (BAUMAN, 2000, p. 147). Tal argumento incita-nos a acreditar que vivemos em um mundo de constante choque de ideias, de forma que quase nada do que emerge na atualidade aparenta ter muito significado ou força para perdurar. Mutação constante pode ser uma expressão adequada para representar nossos dias. Estamos mais do que inseridos em "mais uma crise" na qual mais decisões devam ser tomadas. Coexistimos em um período no qual as possibilidades das mesmas são reduzidas, mas que nos incentiva a repensar paradigmas.

Visando situar melhor o leitor em relação ao assunto que se apresenta, faremos aqui uma sucinta explicação de como entendemos determinados conceitos que aparecem ao longo do texto. São eles: Modernidade, Modernidade Líquida e Pós-Modernidade. Partimos aqui, como Habermas (2002), da Modernidade como um projeto inacabado, em que foi elevada, nos confins do século XVIII, a uma condição filosófica e não mais só histórica. A Modernidade será entendida como um período no qual a racionalidade exerceu influência significativa sobre o homem. Assim, escolhemos consequentemente a denominação de Bauman (2001), referindo-se à atual fase da Modernidade como "modernidade líquida", ou seja, um período fluido, leve e infinitamente mais dinâmico do que a modernidade em si mesma. Por fim, o termo "pós-modernidade" será entendido apenas como um estado de "espírito" filosófico atual que representa uma mudança radical no sistema de práticas e valores oriundos da modernidade (BRACHT; ALMEIDA, 2006).

Esse estado de incerteza, dúvida e mutação observado atualmente parece encontrar suas causas na base do pensamento moderno. Tal pensamento coagiu nossa sociedade a aceitar que a razão é a única forma de encontrar a verdade. Assim, os indivíduos dotados de pouca condição intelectual ou reduzida capacidade de racionalização passaram a ser excluídos ou menosprezados, independente de sua área de atuação.

Isto posto, sustentamos que a onipotência deste pensamento foi desenvolvida e consolidada por meio do rigor associado às inúmeras abordagens metodológicas utilizadas, principalmente no desenvolvimento de pesquisas, bem como na produção dos saberes em todas as áreas. Tal produção foi, ao longo da modernidade, responsável pela criação de normas que visavam ao estabelecimento da ordem e do controle, pretendendo fornecer relatos abrangentes sobre os diversos campos da vida. Weber (citado por BANNELL, 2006, p. 23) corrobora essa ideia e explica que "a modernidade se tornou uma'jaula de ferro' pela dominância da racionalidade instrumental, 
com a consequente transformação do pensamento e da cultura em operações pautadas somente nos critérios de eficiência e sucesso".

Assim, na contemporaneidade, expandiu-se uma forte sensação de que, se algo não pode ser racionalmente comprovado por um bom método, esse algo não pode ser normatizado, logo, não tem significado. Todo tipo de produção do conhecimento, então, passa a ser escravo de um "mentalismo" (TARDIF, 2002, p. 11), no qual se criam redomas que impedem os excluídos de terem um acesso mais detalhado a certos saberes. E os excluídos, por sua vez, curvam-se a significados impostos com os quais, por vezes, não concordam ou cuja origem desconhecem, mas que já estão reconhecidos por uma minoria dotada de "mais razão". Fica, então, a pergunta central de nosso estudo: não há significado fora do que seja estritamente racional ou desamparado do método instrumental?

Tal situação ainda suscita muita discussão e a maneira mais simples de iniciar sua análise pode ser lembrando a clássica pergunta: "quem somos nós?". Tal pensamento nos remete à filosofia kantiana e se transfere, quase que naturalmente, para as questões de Nietzsche quando pensamos: "o que acontece conosco?". Consideramos necessário um entendimento histórico do que a sociedade foi - medieval e dogmática ${ }^{2}$ - e no que ela se tornou moderna e científica. Assim, a questão incerta em Kant - que se propunha transcendental - passa a estar atrelada a uma questão também incerta porém aparentemente mais concreta - nietzschiana (VEIGA-NETO, 2007). Afinal, nossas subjetividades (afetividade, volição, crença, cultura etc.) também são construídas socialmente; e as questões - ou transformações - sociais parecem ser mais facilmente analisáveis e/ou avaliáveis metodologicamente na busca por respostas - algo exigido pelo pensamento moderno.

Parece oportuno, então, tentar entender tal situação por meio da pergunta "como chegamos a ser o que somos?", para assim, poder contestar com mais equilíbrio aquilo que somos, e naturalmente, contestar a situação contemporânea, escapando das coerções individualistas inventadas pela Modernidade (VEIGA-NETO, 2007). A partir dessa contestação, novos olhares se abrirão para fatos que atormentam tantos indivíduos em nossa sociedade, principalmente nas instituições.

Os inúmeros debates que emergem nos campos educacionais, políticos ou científicos, nascem, em boa parte, das críticas ao passado. Por isso, nossa crise atual parece emergir mais especificamente das críticas ao início do período em que vivemos, ou seja, à Modernidade. Inúmeros pensadores mostram-se contrários às suas imposições e argumentam que a razão não seria o único meio de encontrar "respostas". Nietzsche e Freud, 
por exemplo, destacaram-se na transição do século XIX para o século XX, criticando a razão hegemônica e valorizando o sujeito. Kuhn (2000), filósofo da ciência, afirmou que novos paradigmas surgem a cada época, de acordo com as características do momento e dos grupos, transformando, assim, "a verdade". Adorno e Horkheimer (pensadores da Escola de Frankfurt), que influenciaram o pensamento de Habermas, Lyotard e Foucault, entre outros, da chamada "agenda pós-moderna", crítica à coação discursiva racional e às excessivas demandas das abordagens metodológicas.

Contudo, e mesmo considerando algumas peculiaridades significativas, por vezes extremistas, de cada um desses pensadores, a Modernidade demonstra ainda uma tendência a permanecer (mesmo parecendo mais "abalada" em suas estruturas), por vezes ganhando força em seus argumentos e com suas consequências seguindo um caminho natural, como o progresso científico-tecnológico. Outras vezes, a Modernidade dilacera questões mais subjetivas do indivíduo devido ao "afastamento da ética dos domínios da razão" (WEBER, citado por BANNELL, 2006, p. 23), tais como perda de valores, enfraquecimento da cultura e desrespeito à identidade e à diferença.

Nesse contexto de embate com o excessivo racionalismo moderno, que opera com leis funcionais da economia e do Estado, da técnica e da ciência e que se coloca pretensamente imune a quaisquer influências (HABERMAS, 2002), inserimos nosso trabalho visando refletir sobre as principais questões observadas no filme Narradores de Javé. Na película, ciência, identidade, linguagem e poder se confundem, levando-nos a interpretá-lo como um discurso sobre a crise da Modernidade, ${ }^{4}$ portanto, algo bastante atual. Buscamos realizar uma análise crítica apoiada em autores recentes que abordam os temas citados, visando recuperar a relação entre racionalidade e 0 processo histórico orientado à emancipação. Ao longo do texto, utilizaremos as situações descritas no filme para ilustrar as consequências que o excessivo racionalismo instrumental, desenvolvido no pensamento moderno, pode causar sobre a cultura e a identidade de um povo.

Organizamos o texto de modo a destacar aspectos da película que consideramos importantes para a discussão a ser desenvolvida. As relações que estabelecemos com os aspectos selecionados foram arbitrariamente decididas por nós: não se encontram necessariamente no filme ou nas intenções de seus realizadores. Outras escolhas poderiam ter sido feitas. Focalizamos, fundamentalmente, dois pontos que julgamos perpassarem a narrativa do filme: (a) o uso de entrevistas como o recurso primordial para o registro das origens do povoado; (b) as distinções apresentadas entre o 
valor do escrito e do oral. Buscamos, ao enfocar tais aspectos, estímulos para questionar métodos, crenças e valores associados à concepção moderna de construção do conhecimento, bem como para ressaltar a incerteza, o medo e a insegurança que marcam a contemporaneidade.

\section{O FILME E SUAS ENTREVISTAS}

Quais são as expectativas quando se inicia uma pesquisa? Como lidar com as respostas (não) encontradas? Que documentos registram as "verdades"? Quem diz ou escreve o que é ou não é a "verdade"? Estas são algumas questões que podem ser propostas com base no filme Narradores de Javé e que merecem a atenção do pesquisador. De forma bastante incomum e divertida, a obra leva a inestimáveis reflexões.

Inspirado em fatos sobre a vila de Gameleira da Lapa (no interior da Bahia), que foi inundada por um rio, o filme - dirigido por Eliane Caffé - conta a saga de Antônio Biá, homem esperto, malandro e cheio de ideias, que acaba se tornando o responsável por registrar a gloriosa história do Vale de Javé, pacato vilarejo no sertão nordestino prestes a ser inundado devido à construção de uma represa. Seus moradores acreditam que o registro da história do município em um livro poderá ajudá-los a convencer as autoridades a protegêlo e a torná-lo patrimônio cultural, o que o salvaria da inundação. O livro, que será escrito pelo protagonista, deverá ter um caráter "científico", e por isso passa a ser visto pelos habitantes do Vale como "a salvação".

Surge, então, nossa primeira questão. A história da cidade não terá valor se não for "registrada cientificamente" - assim os engenheiros informaram ao povoado que, devido à sua simplicidade, ou melhor, ao seu isolamento, não saberia como registrar a história nos moldes da ciência do homem contemporâneo. É clara a referência aos reflexos do pensamento moderno na sociedade atual. Não há problema se os moradores do Vale de Javé perderem toda sua história e parte de sua identidade. O que importa é um registro à luz da razão. O sacrifício de uma minoria passa a ser "aceitável", pois uma maioria (desconhecida daquela gente) será beneficiada com o advento do progresso, que é representado pela represa.

Bracht e Almeida (2006) sustentam que o uso exclusivo da razão parece ter sido a base para os caminhos da liberdade e autonomia do homem coetâneo. Entretanto, por ter favorecido extremos de relações de poder, que nos dias de hoje chegam a ser imponderáveis (BAUMAN, 1999), por ter exibido a ambivalência do seu significado, bem como por ter produzido sectarismo, autoritarismo, absolutismo, a redução da afetividade e a expulsão do outro (observada integralmente no filme), tal excesso racional implica destruição 
das diferenças e insensibilidade. Os princípios em pauta parecem ter sido capazes de direcionar o indivíduo, ou melhor, a sociedade, a um histórico totalitarismo burocrático, facilmente identificado na contemporaneidade, principalmente nas instituições.

Para tentar atingir o interesse do povoado de Javé, Antônio Biá utilizase de entrevistas, que se tornam um dos pontos centrais do filme. A entrevista é apresentada como discurso de poder: o protagonista demonstra conhecer claramente a força das palavras que usa. De acordo com Bauman (2003, p. 7), "as palavras têm significado: algumas delas, porém, guardam sensações".

Quais são, então, os efeitos dessas entrevistas? Que significados produzem? Ao contarem para Biá a história do lugar, os moradores apresentam diferentes versões, diretamente ligadas à sua memória afetiva, às suas volições ou crenças. Nelas, valorizam seus antepassados, que lhes contaram a história com suas próprias palavras, e terminam por transmitir outras sensações. Destacam-se, então, os conflitos de identidades enaltecidos na trama, exaltados de forma simples e divertida.

Narrada pela memória dos cidadãos locais, a origem de Javé recebe diferentes interpretações. Biá era um homem criativo. Nas palavras do próprio ator José Dumont, ${ }^{5}$ "Biá é um homem que tem mais talento do que caráter". Aproveitou-se, então, das discordâncias entre as histórias para conseguir o respeito dos moradores do vilarejo, do qual havia sido expulso.

Para manter seu emprego no correio da vila (prestes a fechar por falta de movimento), Biá passou a escrever cartas para parentes e amigos de cidades próximas relatando segredos e espalhando mentiras sobre os moradores locais, o que que gerou a ira dos habitantes, culminando em seu isolamento. Contudo, os homens o encontram e argumentam que ele deve "pagar" pelo que fez por meio de seu próprio talento: a escrita.

Em sua primeira entrevista, Biá descobre o nome do fundador de Javé: Indalécio. De acordo com o entrevistado, era um cavaleiro (homem) valente, perspicaz e sempre pronto para a guerra (um herói que guiava o povo fugido de uma terra por ordem de um déspota cruel que queria explorá-la). Antônio depara-se com seu primeiro desafio enquanto escuta o entrevistado: sua narrativa não estava de acordo com sua visão de escrita ideal. Para melhorar o texto, Biá afirma que seria necessário "florear" as linhas daquela história dizendo ao entrevistado que "uma coisa é o fato acontecido, outra é o fato escrito". Acrescentamos: outra também é o narrado. Após convencê-lo de que escreveria o texto depois da entrevista, Biá pergunta ao entrevistado o seu nome. Eis a resposta do cidadão: Vincentino "Indalécio" da Rocha (o mesmo nome do herói). 
Essa pequena passagem parece suficiente para denunciar a impossível imparcialidade dos envolvidos. Uma implicação dessa passagem para o trabalho de pesquisa merece ser destacada: que se espera encontrar e/ou dizer com as investigações?

Em outro momento a obra aborda questão também importante. Passa a ocorrer um processo de negociação da informação: vários indivíduos oferecem sua história para Biá, em função do desejo de serem citados no livro. Ele percebe a autoridade que passa a ter, o que o leva a deliberar com alguns indivíduos quais histórias serão ou não incluídas em "sua" obra. Em suas próprias palavras: "A história pode ser de vocês, mas a escrita é minha".

Por exemplo, para que a história do barbeiro fosse escrita, ele deveria prestar seus serviços (cortes de cabelo e barba) a Biá gratuitamente, por um ano. Por meio dessa passagem somos convidados a refletir sobre os "incentivos" (políticos, corporativos e/ou empresariais) existentes na realização de pesquisas em geral. Que se pode lucrar com os resultados obtidos? Que se produz sob o tênue "véu das intenções"? Estaria o método científico livre de tal influência?

Outros detalhes também podem ser discutidos com base no enredo do conto, já que cada um será capaz de narrá-lo segundo suas interpretações e seus interesses. Destacam-se alguns momentos: (1) são abordadas questões de gênero e identidade, nas quais os heróis são alterados conforme as características do narrador que conta a história durante a entrevista. Após a primeira, na qual Indalécio era um cavaleiro (de mesmo nome do entrevistado), Biá interroga uma mulher. Segundo ela, a heroína entre os fundadores de Javé passa a ser uma mulher guerreira e corajosa, Mariadina, que guia o povo, em vez de Indalécio (o homem), que fracassou devido aos seus ferimentos. Segundo a entrevistada, Mariadina é excluída das histórias justamente por ser mulher. Assim, surgem outras questões importantes como (2) a força latente do feminismo, pois a mulher passa a exercer com eficiência um papel, até então, exclusivo do outro gênero; e (3) a memória com registro oral, pois Mariadina cantava para o povo as divisas de Javé, demarcando seus limites geográficos por meio das cantigas, isto é, da fala. A história do Vale registrava-se, assim, nas canções.

A entrevista com um morador afrodescendente merece destaque. Em seu relato, o herói principal - agora com o nome de Indaleu - também era homem, mas um negro. A narrativa ganha força com seus argumentos. Ao mesmo tempo que o filme nos diz sobre a influência do narrador e as distorções do escritor, também nos sugere a influência exercida na construção da história pelos diversos excluídos da história real em função de diferenças de 
gênero, raça e identidade. Assim como não havia negros nas versões anteriores, não há brancos na nova versão.

A memória explicitada na oralidade é novamente ressaltada, pois o narrador negro contava a história de Javé em seu dialeto africano -sua língua - e por meio de uma cantiga. As origens de Javé são cantadas. O canto, mais uma vez, delimitava uma terra: por meio da linguagem oral, não de um documento escrito, confirmavam-se origem e posse. De forma poética e divertida, a diretora nos conduz, em seu filme, a outros entendimentos de histórias oficiais e nos leva a considerar onde elas foram "gravadas" ou "registradas". O filósofo Barthes (2007, p. 12-13), em sua aula inaugural da cadeira de Semiologia Literária no Colégio da França, esclarece que "a linguagem, ou sua expressão obrigatória, a língua, inscreve o poder através dos tempos, desde toda eternidade humana [...] a linguagem é uma legislação, a língua é seu código".

Se recorrermos a Foucault (2007) para a análise de tais argumentos, poderemos verificar que, se a linguagem exprime, não o faz para multiplicar as coisas, mas sim para traduzir o querer fundamental ou o desejo daqueles que falam. Tudo aquilo que é dito - neste caso, as visões das origens de Javé - está muito mais ligado aos desejos dos que proferem o discurso do que às suas próprias percepções "reais" dos fatos. $O$ discurso se apresenta mais "encharcado" do próprio sujeito que de sua memória, ou ainda, que do próprio fato descrito. A trama em questão nos favorece a compreensão de que os discursos forjam nossas formas de enxergar e entender o mundo, bem como de descrevê-lo. As origens do Vale de Javé aparecem moldadas historicamente pelos diferentes discursos proferidos pelos personagens. Ou seja, os discursos "são práticas que formam sistematicamente os objetos de que falam" (FOUCAULT, 2008, p. 55).

\section{O FILME E A RELAÇÃO ENTRE O ESCRITO E O ORAL}

Outro ponto que desejamos destacar é como o povoado se relaciona com sua cultura, entendida aqui como prática de significação, ou melhor, como prática daquilo que tem sentido. Habermas (citado por BANNELL, 2006) acentua que a cultura é um "motor" da evolução social. Na terceira metade do filme, os moradores são filmados e, assim, têm a oportunidade de expor seus medos, incertezas, angústias e aflições referentes à chegada da represa (progresso moderno). Bauman (2005) esclarece que, quando nos deparamos com as incertezas provenientes da "Modernidade líquida", nossas identidades sociais, culturais ou religiosas passam por uma transformação contínua [...] com todas as angústias que tal situação suscita. 
Observemos o discurso desesperado de uma moradora local: "Eu tenho meus pais, o meu marido... tudo enterrado ali, naquele cemiterinho ali... eu tenho uma filha... Então nós queremos ficar aqui... pra sempre ir lá, colocar as velas na sepultura dele [...] os engenheiros não tem que tirar nós daqui não... eles não vão tirar nós daqui não, de jeito nenhum!"E continua mais adiante: "Não dá... não dá, você acha que nós vamos viver debaixo d'água? Os nossos mortos vão viver debaixo d'água? Não pode...."

Questões de crença, hábito e cultura expressam-se na linguagem, ilustrando sua importância no processo constante de construção de nossas identidades (MOREIRA, 2006). Evidencia-se o último recurso na luta travada pelos habitantes contra seus invasores. Essa luta, acrescentemos, foi muito mais decidida por questões econômico-políticas do que por razões científicas (como o vilarejo ingenuamente acreditava). A identidade preponderante de um grupo poderoso definiu, a despeito das resistências, o destino de um povoado, cuja história não havia sido registrada "oficialmente".

O protagonista Antônio Biá sempre soube que o povoado estava sendo enganado. Por isso, deparava-se com uma difícil missão: narrar uma história a partir de versões diferentes, de vários fragmentos e de memórias incongruentes, que de nada serviriam. Ele se vê entre a impossibilidade de uma boa escrita ("floreada", metódica e organizada) e a inevitabilidade de um futuro destruidor. Para Biá, a cidadezinha seria aniquilada de qualquer maneira, com ou sem livro de registros. Ele apreciava os significados das histórias e os entendia, mas sabia que só "existiam" para o próprio vilarejo.

Ele também não sabia como representá-los no livro. Na parte final da história, manda um recado ao povoado: "quanto às histórias de Javé, melhor é ficarem na boca do povo, porque no papel não há mão que lhes dê razão". O personagem compara escrita e oralidade, aparentemente criticando a segunda. Contudo, sustentamos não ser prudente valorizar uma em detrimento da outra, já que ambas se enfraqueceriam. "Ao colocar a oralidade em contraposição à escrita estamos buscando reinstalar a voz do lugar onde foi, de certa forma, expulsa ou abafada" (GARCIA; CASTANHEIRA, 2007, p. 8-9). Os autores explicam que formas de aprendizagem podem se perder pela hegemonia de um conhecimento grafocêntrico, em que o olhar se sobrepõe à escuta.

A racionalidade de Biá e os conhecimentos por ele adquiridos levaram-no a uma percepção mais clara do futuro destruidor e, ao mesmo tempo, a uma intolerância que o fez desistir de ajudar a vila. Contudo, o malandro não quis divulgar sua percepção com antecedência, pois dessa forma perderia seu poder, assim como os privilégios e a fama que a situação 
Ihe oferecia. Assim, ele estendeu a situação até o limite, sempre acreditando que a metodologia racional e organizada da escrita do livro ${ }^{6}$ seria insuficiente para convencer as autoridades a respeito do significado oral da origem do vale.

Neste contexto, em que se traz à tona a relação entre escrita e oralidade, lançamos mais uma reflexão: até que ponto tem valor o que não está escrito? Ainda ouvimos a expressão popular: eu te dou a minha palavra (de honra, de homem, de escoteiro etc.)? Em que momento o que está escrito (burocraticamente) vence a palavra dita (oralmente)? Em uma escola, por exemplo, em que situação as decisões burocráticas valem mais que as pedagógicas? Por que Javé só teria "valor" se estivesse registrada na forma escrita?

De acordo com Sennett (2006), a sociedade moderna está em revolta contra o tempo burocrático, que pode paralisar o trabalho, o governo e outras instituições. $\mathrm{Na}$ atualidade, muitas decisões importantes na política, economia ou educação esbarram em questões burocráticas que, por vezes, impedem seu andamento ou sua eficiência. O homem moderno mostra-se também incapaz de tomar decisões "longe do papel", pois há algo que parece espreitá-lo constantemente, gerando receio e dúvida. Só se cumprem ordens que estão escritas, assinadas e autenticadas, pois assim pode-se provar, em caso de problemas, que a "culpa" é do outro. A burocracia, então, passa a existir devido à desconfiança produzida pela fragilidade do caráter humano. Se um homem não"registra" o que disse, o outro não pode controlá-lo e viceversa, ou seja, passa a existir uma relação incerta e viciosa de medo. Segundo Bauman (2006), as certezas se foram e, com elas, os sonhos de controle sobre o mundo desapareceram, surgindo então um "medo líquido" generalizado.

Ao tratar do medo em sua trama, a diretora não o apresenta de modo "oficial". O medo vem pela ameaça inserida no discurso dos próprios cidadãos do Vale de Javé e se espalha. Os engenheiros responsáveis pelo surgimento do "progresso" (a represa) que ameaçava o vilarejo aparecem na história como meros figurantes que apenas "transitam ali e acolá", medindo e preparando calmamente a desgraça alheia. Suscitam, então, uma reflexão sobre a representação da onipresença do pavor. O medo se torna maior em nosso tempo porque é incerto, espalhado, disperso e sem um local fixo. Portanto, pode ser lobrigado e imaginado, mas nunca visto em sua plenitude. Ele existe, mas não sabemos de onde vem. Bauman $(2006$, p. 8) acrescenta: "A escuridão não constitui a causa do perigo, mas é o habitat natural da incerteza - e, portanto, do medo". No filme em questão, assim como na contemporaneidade, incerteza, progresso e medo caminham de mãos dadas, gerando, por vezes, o caos. 


\section{CONSIDERAÇÕES FINAIS}

Narradores de Javé sugere que a verdade está estabelecida por "estabelecidos", que parecem ser os privilegiados da ciência moderna. Essa ciência compreende os conhecimentos verdadeiros, instrumentais, racionais e burocráticos, que não consideram o sujeito e suas identidades diferenciadas. Antes de continuar, cabe esclarecer ao leitor que não valorizamos caminhos que se sustentam em ilusões subjetivas (ou que se centram na objetividade do conhecimento essencialmente moderno). Acreditamos nas transformações práticas e linguagens diferenciadas que nos tornaram o que somos. Assim, sustentamos que o "conhecimento científico, como a linguagem, é intrinsecamente a propriedade comum de um grupo ou então não é nada. Para entendê-lo, precisamos conhecer as características essenciais dos grupos que o criam e o utilizam" (KUHN, 2000, p. 257). Observamos que o Vale de Javé apresentava os significados expressos na linguagem do povo.

Defendemos, então, um caminho de equilíbrio entre objetividade e subjetividade, com base no qual ambas orientem os processos de percepção e interpretação de fatos, pois "a interpretação começa onde a percepção termina. Os dois processos não são o mesmo e o que a percepção deixa para a interpretação completar depende drasticamente da natureza e da extensão da formação e da experiência prévias" (KUHN, 2000, p. 244), ou seja, depende, também, de questões subjetivas. Em Narradores de Javé, percebemos o progresso e seu radicalismo objetivo destruindo uma história local (cabe ressaltar, aqui, a ausência da solidariedade e do respeito). Questionamos: será que a represa não poderia ter sido construída sem a destruição da vila? Do mesmo modo, quantas pequenas histórias locais e verídicas já não podem ter sido destruídas através dos tempos, com a criação de novas "verdades" impostas, que moldaram nossa forma de ser?

Historicamente, vimos, no século XV, uma transição social marcada pelo radicalismo dos métodos racionais, entre o dogmatismo medieval e o humanismo renascentista, transição essa que prenunciava o período moderno com suas novas teorias filosóficas e científicas (MARCONDES, 2007). Criou-se uma ruptura que, apesar de sua importância, parece ter também colaborado para que a sociedade contemporânea se tornasse um mundo de incertezas e medo. Talvez seja então necessário entender que tal radicalismo pode ser útil apenas para que se rompam grilhões de atavismos e surjam questionamentos que levam a novos paradigmas. Contudo, a permanência de tais pensamentos extremistas levou o homem a excessos - assim como ocorreu com todos os 
desequilíbrios do século XX, como, por exemplo, seus inúmeros "ismos"e suas cruéis guerras sangrentas.

Sustentamos que, a caminho da "pós-modernidade", é possível encontrar um paradoxo, isto é, um "excesso de ausência" de significados - algo que pode estar ocorrendo em virtude dos excessos de significados oriundos dos métodos da Modernidade. É plausível afirmar que a Modernidade gera a "pós-modernidade", pois ela "se move por si própria e se autonomiza em sua evolução" (HABERMAS, 2002, p. 6). Tal autonomia parece não só refletir o progresso científico, mas também o caos. Se lembrarmos - em tom de ironia - a máxima da física newtoniana (clássica): para toda ação temos uma reação igual e contrária; ou ainda (e não menos importante), um dos fundamentos da física quântica, desenvolvida na Modernidade, o princípio da incerteza, ${ }^{7}$ segundo o qual o determinismo perde espaço para as probabilidades, nossa afirmativa pode ser justificável.

A ordem buscada tão intensamente pelos padrões modernos passa a causar uma desordem que a atinge, de forma incerta ou imprecisa, diríamos, em "módulo". Afinal, não se pode medir o caos, mas ele existe e parece ter significado. Assim como o medo. E ambos tomaram conta de Javé. A convivência com essa consciência, isto é, com tal incômodo, é chamada por Bauman (1998) de "mal-estar da pós-modernidade". Indagamos: se permanecermos por muito tempo neste paradoxo - tal como se apresenta na contemporaneidade - quais serão os "ismos" dos próximos séculos? Se as guerras foram consequências de excessos de significados, quais serão as consequências de sua ausência?

Bracht e Almeida (2006) debruçam-se sobre uma profunda desconfiança, por parte do pós-modernismo, a respeito da pretensão totalizante e/ou universalizante de saber existente no pensamento moderno. Para os autores, o pós-modernismo apresenta-se muito mais fecundo no que revelam de contrário à Modernidade: na contingência, nas particularidades, nas microestruturas. Ou seja, na incerteza em relação ao que acontecerá ou não. Ao mesmo tempo, prosseguem os autores, tal prática (pós-moderna) possui antinomias tão destruidoras quanto as que encontramos no projeto moderno.

Concluindo, afirmamos que o homem "evidentemente mente" e que o exclusivo uso dos métodos burocráticos e científicos como norteadores da verdade ainda são formas necessárias de se tentar encontrar alguma segurança na atualidade. Porém, as águas fluviais do final do filme, que invadiram o vale (e que significavam o progresso, isto é, a chegada da "Modernidade" no sertão), parecem consolidar o fracasso da ciência burocrática, extremista e 
impiedosa, tal como apresentada no enredo. Apropriando-nos de palavras de Bauman (2001), poderíamos afirmar: salve-se quem puder da "liquidez" científica (já que ela inunda)! Segundo o autor, o termo (liquidez) mostra-se uma metáfora adequada para representar a natureza da atual fase na história da Modernidade.

Narradores de Javé é um filme marcante, sobre ciência, discurso e poder. O poder da língua e das palavras. Uma fábula sobre a crise da Modernidade, que ainda aborda questões sobre a importância da identidade, da cultura, das crenças do povo e de suas relações com a terra. Na história, os diálogos fluem com uma prazerosa naturalidade, o que não pode ser totalmente explicado pela razão, mas talvez o possa pela criatividade e sensibilidade de indivíduos que usam a palavra de forma ambígua, malandra, poética, indomável e (por que não?) inteligível. A nós, o enredo provocou reflexões cruciais sobre a contemporaneidade e o conhecimento que temos construído acerca do indivíduo, da sociedade, do mundo e da natureza.

\section{NARRADORES DE JAVÉ: ARGUMENTS TO THINK ABOUT MODERNITY}

ABSTRACT:This paper discusses the crisis of Modernity, using as a basis the issues raised in the movie Narradores de Javé, directed by Eliane Caffé. It can be asked: what kind of document registers the "truth"? Who can say what is and what is not "truth"? What is the difference between what is said and what is written? Can we find meaning without "method"? The movie provides valuable reflections on the existing conflict between the supposed modern scientism and its "post-modern" consequences.

KEYWORDS: Modernity. Postmodernity. Meaning.

\section{NOTAS}

1. Destacamos alguns em áreas distintas:Thomas Kuhn (epistemologia), Zygmunt Bauman (sociologia), Jürgen Habermas (Filosofia), entre outros não menos importantes.

2. Referimo-nos aqui, basicamente, ao período da "escolástica" (século XI ao XIV), que aceitava os dogmas do cristianismo, cuja discussão filosófica era proibida sobre eles embora na prática isso não tivesse ocorrido, pois se destacaram nessa fase pensadores como São Tomás de Aquino e Guilherme de Ockham, homens religiosos, mas ligados a importantes universidades da época, e que influenciaram o pensamento a partir de então (MARCONDES, 2007).

3. Entendemos que esta "agenda pós-moderna" reúne perspectivas teóricas como o pós-estruturalismo, o pós-modernismo, os estudos feministas e de gênero, os estudos multiculturais, os estudos étnicos, a teoria queer etc. Para um detalhamento, ver Bracht e Almeida (2006). 
4. Não se trata aqui de afirmar que a direção ou a produção do filme tenha tido ou não a intenção de retratar o tema. Também não nos interessa se os profissionais envolvidos têm refletido sobre a questão. O que almejamos é utilizar a obra como "pano de fundo" para ilustrar conceitos recentes e contemporâneos sobre a crise da Modernidade e suas consequências.

5. Entrevista cedida pelo ator, incluída na faixa extra do DVD.

6. Naturalmente, entendemos que o personagem não faz uma distinção entre os termos por nós empregados.

7. O princípio da incerteza consiste em um enunciado da mecânica quântica, formulado por Werner Heisenberg, impondo restrições à precisão com que se podem efetuar medidas simultâneas de uma classe de pares de observáveis. Quanto mais se focaliza uma propriedade, mais a medição da outra se perde na incerteza (ARNTZ; CHASSE; VICENTE, 2007).

\section{REFERÊNCIAS}

ARNTZ, W.; CHASSE, B.; VICENTE, M. Quem somos nós? A descoberta das infinitas possibilidades de alterar a realidade diária. Rio de Janeiro: Prestígio Editorial, 2007.

BANNELL, R. I. Habermas \& a educação. Belo Horizonte: Autêntica, 2006.

BARTHES, R. Aula. São Paulo: Cultrix, 2007.

BAUMAN, Z. O mal-estar da pós-modernidade. Rio de Janeiro: Jorge Zahar, 1998.

BAUMAN, Z. Globalização: as consequências humanas. Rio de Janeiro: Jorge Zahar, 1999.

BAUMAN, Z. Em busca da política. Rio de Janeiro: Jorge Zahar, 2000.

BAUMAN, Z. Modernidade líquida. Rio de Janeiro: Jorge Zahar, 2001.

BAUMAN, Z. Comunidade: a busca por segurança no mundo atual. Rio de Janeiro: Jorge Zahar, 2003.

BAUMAN, Z. Identidade. Rio de Janeiro: Jorge Zahar, 2005.

BAUMAN, Z. Medo líquido. Rio de Janeiro, Jorge Zahar, 2006.

BRACHT, V.; ALMEIDA, F. Emancipação e diferença na educação: uma leitura com Bauman. Campinas, SP: Autores Associados, 2006.

CAFFÉ, E. Narradores de Javé. Bananeira Filmes, 2003.

FOUCAULT, M. As palavras e as coisas. 9. ed. São Paulo: Martins Fontes, 2007.

FOUCAULT, M. A arqueologia do saber. 7. ed. Rio de Janeiro: Forense-Universitária, 2008.

GARCIA, P. B.; CASTANHEIRA, M. (Orgs.). Educação e identidade: formação, oralidade e memória. Rio de Janeiro: Publit Soluções Editoriais, 2007. 
HABERMAS, J. O discurso filosófico da modernidade. São Paulo: Martins Fontes, 2002.

KUHN, T. A estrutura das revoluções científicas. 5. ed. São Paulo: Perspectiva, 2000.

MARCONDES, D. Iniciação à história da filosofia: dos pré-socráticos a Wittgenstein. 11. ed. Rio de Janeiro: Jorge Zahar, 2007.

MOREIRA, A.F.B. Desafios contemporâneos no campo da educação: a questão das identidades. In: MOREIRA, A. F. B.; PACHECO, J. A. (Orgs.). Globalização e educação: desafios para políticas e práticas. Porto: Porto Editora, 2006.

SENNETT, R. A corrosão do caráter: as consequências pessoais do trabalho no novo capitalismo. 11 ed. Rio de Janeiro: Record, 2006.

TARDIF, M. Saberes docentes e formação profissional. Petrópolis: Vozes, 2002.

VEIGA-NETO, A. Foucault \& a educação. Belo Horizonte: Autêntica, 2007.

Cláudio Pellini Vargas, doutorando em Educação pela Universidade Federal de Juiz de Fora/MG.

E-mail: prof.pellini@yahoo.com.br

Antonio Flafio Barbosa Moreira, doutor em Educação pela Universidade de Londres e coordenador do Programa de Pós-graduação em Educação da UCP/RJ. 